\title{
Caffeine or theophylline for neonatal apnoea?
}

\author{
J E M Scanlon, K C Chin, M E I Morgan, G M Durbin, K A Hale, S S Brown
}

Regional Neonatal Intensive Care Unit, Birmingham Maternity Hospital, Institute of Child Health,

Birmingham

J E M Scanlon

K C Chin

M E I Morgan

G M Durbin

Regional Laboratory

for Toxicology,

Dudley Road Hospital,

Birmingham

$\mathrm{K}$ A Hale

S S Brown

Correspondence to: Dr J E M Scanlon, Department of Paediatrics, Southampton General Hospital, Tremona Road, Southampton SO9 4XY.

Accepted 13 December 1991

No reprints available.

\begin{abstract}
Caffeine, in the dose usually recommended $(12.5 \mathrm{mg} / \mathrm{kg}$ loading dose and $3 \mathrm{mg} / \mathrm{kg}$ daily maintenance), and a higher dose regimen ( 25 $\mathrm{mg} / \mathrm{kg}$ loading and $6 \mathrm{mg} / \mathrm{kg}$ daily maintenance), was compared with theophylline $(7.5 \mathrm{mg} / \mathrm{kg}$ loading and $3 \mathrm{mg} / \mathrm{kg}$ thrice daily maintenance). The study was a randomised controlled trial in the treatment of a group of 44 infants of less than 31 weeks' gestation (mean gestational age 28.3 weeks) who were suffering from frequent apnoeic attacks. All three regimens produced a significant reduction in apnoeic attacks within 24 hours, but only the higher dose caffeine and theophylline groups showed a significant improvement in apnoea within eight hours.

The use of caffeine for the treatment of neonatal apnoea is recommended, because a once daily dose is more easily administered, and because it was found that plasma concentrations were more predictable than those of theophylline. If used in very preterm infants, however, its is suggested that a higher dose regimen than that previously recommended be used to achieve a faster response.
\end{abstract}

Neonatal apnoea is a common problem: it occurs in $25 \%$ of infants under $2500 \mathrm{~g}$ and $80 \%$ of infants under $1000 \mathrm{~g} .{ }^{12}$ With smaller babies now forming a large percentage of the population of neonatal intensive care units, the management of neonatal apnoea is an important part of the clinical workload.

The methylxanthines-theophylline (and aminophylline) and caffeine-are widely used for the treatment of this condition. ${ }^{3}$ Theophylline has been the drug most commonly used to treat neonatal apnoea in the UK. ${ }^{45}$ Caffeine, however, has many potential advantages: it has a higher therapeutic ratio, it is absorbed more reliably when administered enterally and has a longer half life, thus enabling the drug to be administered only once daily. ${ }^{6}$ Caffeine has also been shown to be effective in apnoeic infants who are unresponsive to theophylline. ${ }^{7}$

Comparisons of the two drugs have been reported before, ${ }^{8-10}$ but these studies have either included a high proportion of more mature infants (of 31 or 32 weeks' gestation), excluded oxygen dependent infants or included infants with as few as three apnoeas per day. They therefore failed to reflect the day to day problems in most neonatal intensive care units in their management of very preterm infants with apnoeic attacks.

In a pilot study we formed an impression that a higher dose of caffeine than that previously recommended was required to treat effectively infants of lower gestational age. This study was therefore designed to compare the efficacy of theophylline with that of caffeine administered in two different dose regimens to a group of very preterm infants with frequent and clinically significant apnoeic attacks.

\section{Patients and methods \\ PATIENT SELECTION}

Infants were included in our study if they were less than 31 weeks' gestation at birth and if they had either 10 (or more) apnoeic attacks in eight hours or four apnoeas in one hour. Apnoea was defined as a drop in heart rate of more than $\mathbf{4 0}$ beats/minute (bpm) below the resting heart rate in an infant who was not breathing, and who required stimulation to correct the problem.

Infants prospectively entering the trial were randomly allocated (by random numbers in sealed envelopes) to one of three treatment groups. Group $A$ ('standard dose caffeine') - a loading dose of $25 \mathrm{mg} / \mathrm{kg}$ caffeine citrate $(12.5$ $\mathrm{mg} / \mathrm{kg}$ caffeine) and a maintenance dose of $6 \mathrm{mg} / \mathrm{kg}$ caffeine citrate ( $3 \mathrm{mg} / \mathrm{kg}$ caffeine) once daily were given to produce a desired plasma concentration of $15 \mathrm{mg} / \mathrm{l}$ caffeine (range 13-20 $\mathrm{mg} / \mathrm{l}$ ). Group $B$ ('higher dose caffeine')-a loading dose of $50 \mathrm{mg} / \mathrm{kg}$ caffeine citrate (25 $\mathrm{mg} / \mathrm{kg}$ caffeine) and maintenance dose of $12 \mathrm{mg} / \mathrm{kg}$ (6 mg/kg caffeine) once daily were given to produce a desired plasma concentration of $30 \mathrm{mg} / 1$ (range $26-40 \mathrm{mg} / \mathrm{l}$ ). Group $C$ ('theophylline') - a loading dose of $7.5 \mathrm{mg} / \mathrm{kg}$ theophylline and a maintenance dose of $3 \mathrm{mg} / \mathrm{kg}$ theophylline three times daily were given to produce a desired plasma concentration of $15 \mathrm{mg} / \mathrm{l}$ (range 13-20 mg/l).

In all three treatment groups the maintenance dose of the drug was adjusted if the plasma concentrations were out of the desired range, but in none of these patients were such adjustments made within 48 hours of starting treatment. As theophylline is metabolised into caffeine in the premature infant, ${ }^{11}$ the cumulated caffeine plus theophylline concentrations in this group were kept below $25 \mathrm{mg} / \mathrm{l}$.

\section{DRUGS}

The drugs were usually given orally or via a nasogastric tube. The preparations used for oral administration were caffeine citrate in chloroform water ( $20 \mathrm{mg}$ caffeine citrate/ml) and theophylline hydrate in $90 \%$ alcohol diluted with water $(3 \mathrm{mg}$ theophylline/ml). Although 
these are the preparations that we are still using, recent work has shown that the preservatives in these mixtures (that is, chloroform water and $\mathbf{9 0 \%}$ alcohol) are not essential, and that caffeine and theophylline are pharmacologically stable and microbiologically safe for a period of one week having been made up in purified water and stored in a refrigerator (Tina Crook, Royal Berkshire Hospital, pharmacy departmentpersonal communication).

When using the 'higher dose caffeine' regimen the loading dose was administered in two separate doses of $25 \mathrm{mg} / \mathrm{kg}$ caffeine citrate given orally one hour apart, in order to avoid the possibility of the infant vomiting because of the volume load.

Caffeine citrate $0.99 \%$ (caffeine citrate 10 $\mathrm{mg} / \mathrm{ml}$ )_both loading dose and maintenance doses infused daily over half an hour-and aminophylline injection (aminophylline 25 $\mathrm{mg} / \mathrm{ml}$ )_administered as a continuous infusion-were available as alternatives to oral or nasogastric treatment in our trial. None of the infants in group B (higher dose caffeine) or group C (theophylline) received intravenous treatment. Only two infants in group A (standard dose caffeine) received intravenous caffeine, and neither their clinical response nor the plasma concentrations of caffeine different appreciably from the other infants in that group. We have treated large numbers of other infants with both caffeine citrate and aminophylline administered intravenously, and have observed no differences, clinically or with plasma concentrations, related to route of administration.

\section{MEASUREMENTS OF PLASMA CONCENTRATIONS OF THE DRUGS}

Blood samples for measurement of drug concentrations were obtained at the same time as blood sampling for other routine tests: all were heparinised capillary samples taken from the heel. They were obtained daily for five days, starting the day after the loading dose, and twice during the course of the next week. Plasma theophylline and caffeine concentrations were determined by high performance liquid

Table 1 Characteristics of infants entering the trial $(n=44)$. Weight and age figures are mean $(S D)$

\begin{tabular}{|c|c|c|c|c|c|}
\hline & $\begin{array}{l}\text { No of } \\
\text { infants }\end{array}$ & $\begin{array}{l}\text { Birth weight } \\
(\mathrm{g})\end{array}$ & $\begin{array}{l}\text { Gestational } \\
\text { age } \\
\text { (weeks) }\end{array}$ & $\begin{array}{l}\text { Postnatal } \\
\text { age } \\
\text { (days) }\end{array}$ & $\begin{array}{l}M: F \\
\text { ratio }\end{array}$ \\
\hline $\begin{array}{l}\text { Group A (standard dose caffeine) } \\
\text { Group B (higher dose caffeine) } \\
\text { Group C (theophylline) }\end{array}$ & $\begin{array}{l}16 \\
14 \\
14\end{array}$ & $\begin{array}{l}1140(210) \\
1200(260) \\
1240(320)\end{array}$ & $\begin{array}{l}28 \cdot 7(1 \cdot 2) \\
28 \cdot 2(1 \cdot 1) \\
27 \cdot 9(1 \cdot 4)\end{array}$ & $\begin{array}{l}5 \cdot 6(2 \cdot 6) \\
6 \cdot 0(2 \cdot 7) \\
7 \cdot 6(4 \cdot 9)\end{array}$ & $\begin{array}{l}9: 7 \\
7: 7 \\
8: 6\end{array}$ \\
\hline
\end{tabular}

Table 2 Effect of treatment in reducing the number of apnoeas. Figures are mean (SE)

\begin{tabular}{|c|c|c|c|}
\hline & \multicolumn{3}{|c|}{ Reduction in the number of apnoeas } \\
\hline & $\begin{array}{l}\text { No of apnoeas/ } \\
24 \text { hours }(\text { day } 0)\end{array}$ & $\begin{array}{l}\text { Reduction between } \\
\text { day } 0 \text { and day } 1\end{array}$ & $\begin{array}{l}\text { Reduction between } \\
\text { day } 0 \text { and day } 2\end{array}$ \\
\hline $\begin{array}{l}\text { Group A (standard dose caffeine) } \\
\text { Group B (higher dose caffeine) } \\
\text { Group C (theophylline) }\end{array}$ & $\begin{array}{l}22 \cdot 81(0 \cdot 49) \\
22 \cdot 79(0 \cdot 72) \\
24 \cdot 07(0 \cdot 70)\end{array}$ & $\begin{array}{l}-6.94(0.69)^{*} \\
-12.79(0.63)^{* * *} \\
-13.86(0.86)^{* *}\end{array}$ & $\begin{array}{l}-12.50(0.67)^{* * *} \\
-17 \cdot 14(0.57) \\
-20.36(0.74)\end{array}$ \\
\hline
\end{tabular}

Significance: ${ }^{*} 0.05>p>0.02 ;{ }^{* *} 0.01>p>0.001 ;{ }^{* * *} p<0.01$.

Day 0 is the day before treatment started. chromatography on $100 \mu \mathrm{l}$ of plasma (minimum $50 \mu$ l plasma).

\section{STATISTICS}

Statistical analysis of results was performed using Fisher's exact test and Student's paired $t$ test as appropriate.

This project was approved by the ethical committee of Central Birmingham Health Authority.

\section{Results}

Over a two year period 44 infants were entered into the study. Of the 44 infants, $32(73 \%)$ had previously been ventilated and $43(98 \%)$ were still oxygen dependent at the time of entry to the study. Twenty six infants (59\%) were boys and $37(84 \%)$ were white.

Although every attempt was made to exclude other causes of apnoea, eight infants were subsequently found to have other problems and it became clear that their apnoeic attacks were secondary to these other diagnoses: four infants had proven infection (pneumonia and septicaemia with positive blood cultures), two infants had significant neurological abnormality (bilateral periventricular leucomalacia with subsequent abnormal neurological development) and two had severe oesophageal reflux (as demonstrated by an intraoesophageal $\mathrm{pH}$ probe. ${ }^{12}$

Table 1 shows the characteristics of the infants in the trial. There were no significant differences between the groups in weight, gestational age, or postnatal age and the sex distribution of the infants within the groups showed an approximately equal male to female ratio.

\section{RESPONSE TO TREATMENT}

The number of apnoeas (over a 24 hour period) decreased dramatically over two days from the start of treatment in all three groups, but was most significant in the high dose caffeine and theophylline groups.

As can be seen in table 2, which includes the results from all infants entered, the number of apnoeas/day was reduced by a third within 24 hours by treatment with standard dose caffeine. It was, however, reduced by over $50 \%$ by the higher dose caffeine and theophylline treatments within the same time period. Although a further reduction was observed in the standard dose caffeine group by 48 hours, some infants in the other groups had, by then, had their apnoeas eliminated completely.

We defined successful treatment as a $>50 \%$ reduction in the number of apnoeas (as measured over an eight hour period). Only one infant, other than those whose apnoea was retrospectively found to be secondary to another diagnosis, failed to respond within 48 hours of the start of treatment. The response to treatment is illustrated in table 3: those infants who subsequently had other pathology are excluded, rather than being described as 'failures'.

In group A only four of the 12 infants responded to treatment within eight hours. 
Table 3 Response to treatment, where success is defined as $>50 \%$ reduction in the number of apnoeas

\begin{tabular}{|c|c|c|c|c|c|}
\hline & \multicolumn{3}{|c|}{ Success } & \multirow[t]{2}{*}{ Failed } & \multirow[t]{2}{*}{ Excluded } \\
\hline & $\begin{array}{l}<8 \\
\text { hours }\end{array}$ & $\begin{array}{l}<24 \\
\text { hours }\end{array}$ & $\begin{array}{l}<48 \\
\text { hours }\end{array}$ & & \\
\hline $\begin{array}{l}\text { Group A (standard dose caffeine) } \\
\text { Group B (higher dose caffeine) } \\
\text { Group C (theophylline) }\end{array}$ & $\begin{array}{r}4 \\
10 \\
11\end{array}$ & $\begin{array}{l}2 \\
1 \\
1\end{array}$ & $\begin{array}{l}5 \\
1 \\
0\end{array}$ & $\begin{array}{l}1 \\
0 \\
0\end{array}$ & $\begin{array}{l}4 \\
2 \\
2\end{array}$ \\
\hline
\end{tabular}

Comparing success at 8 hours: group $B>$ group $A \mathrm{p}=0 \cdot 036$; group $\mathrm{C}>$ group $\mathrm{A} p=0 \cdot 01$.

Another seven had a $>50 \%$ reduction in apnoeas by the end of 48 hours. Only one infant failed to respond (no explanation for this failure could be found). Two infants in this group received their treatment parenterally: one responded with a reduction in apnoeas of $>50 \%$ within eight hours, the other took 48 hours to respond in the same way. There were no differences observed between these two infants and the rest of the group (clinically or in their plasma concentrations).

In group B 10 of the 12 infants responded to treatment within eight hours. Another two had responded by the end of 48 hours. There were no failures in this group.

In group C 11 of the 12 infants responded to treatment within eight hours. Another had responded by 48 hours. There were no failures in this group either.

All eight infants who were retrospectively excluded failed to respond with a $>50 \%$ reduction in apnoeas within 48 hours of starting treatment. Three of the infants who responded to treatment also had other problems: two with periventricular leucomalacia, both in group $C$, and one with oesophageal reflux in group $B$. The two with periventricular leucomalacia, however, had unilateral lesions (and a better neurological outcome than those with bilateral lesions who were excluded); and the infant with oesophageal reflux appeared to have less severe reflux, although it may have remained a cause of apnoea (he had a $>50 \%$ reduction in apnoeas within eight hours, but then persisted with a small number of severe apnoeic attacks each day).

\section{PLASMA DRUG CONCENTRATIONS}

The figure shows the plasma drug concentrations in the three treatment groups on the first, third, and fifth day after starting treatment (approximately 24, 72, and 120 hours after starting treatment respectively). The mean (SD) plasma concentrations of caffeine in group A on days 1 , 3 , and 5 were $15 \cdot 43(5 \cdot 11), 15 \cdot 31(3 \cdot 93)$, and $15 \cdot 81(2 \cdot 90) \mathrm{mg} / 1$ respectively. In group $B$ the plasma concentrations of caffeine were: 30.42 (4.05), 32.92 (4.88), and $33 \cdot 36(5 \cdot 27) \mathrm{mg} / \mathrm{l}$. The plasma concentrations of theophylline in group C were: $10.87(3.52), 14.96(6.00)$, and $17 \cdot 22$ $(3 \cdot 19) \mathrm{mg} / \mathrm{l}$.

Over the 10 days during which plasma drug concentrations were monitored, $69 \%$ of the measurements on infants in group $A$ showed drug concentrations in the desired range (caffeine $13-20 \mathrm{mg} / \mathrm{l}$ ), and $73 \%$ of the assays on infants in group $B$ were in the desired range (caffeine $26-40 \mathrm{mg} / \mathrm{l}$ ). In contrast, only $56 \%$ of

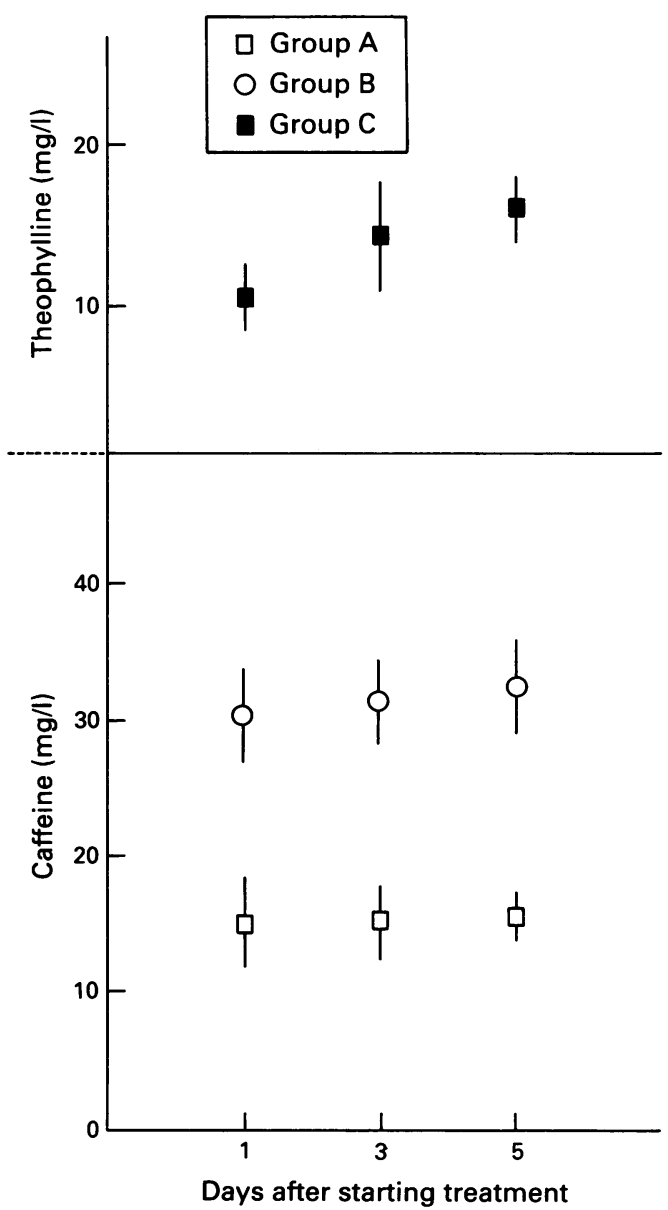

Plasma drug concentrations, shown as mean (SD). Group A: standard dose caffeine; group $B$ : higher dose caffeine, and group $C$ : theophylline.

the measurements on infants in group $\mathrm{C}$ showed plasma drug concentrations in the desired range (theophylline $13-20 \mathrm{mg} / \mathrm{l}$ ).

\section{SIDE EFFECTS}

Plasma concentrations of theophylline $>20 \mathrm{mg} / 1$ were associated with a persistent tachycardia (of $>195 \mathrm{bpm}$ ), necessitating a dosage reduction, in two infants. Five of the 12 infants in group $\mathrm{C}$ required dosage adjustments, or individual dose omissions on at least two occasions, because of a tachycardia of $>195 \mathrm{bpm}$. Only one of the infants in group $A$, and none of the infants in group B, needed dosage adjustments because of tachycardia. Apart from this one infant whose tachycardia may have been attributable to treatment, no side effects were apparent with caffeine, even when an error occurred in calculation of the caffeine dose (on the fourth day of treatment in one child), and a plasma concentration of $68 \mathrm{mg} / \mathrm{l}$ was measured.

The maximum effect on heart rate (the average of all 24 on-the-hour recordings by nursing staff expressed as bpm) was observed on the fourth day of treatment, with a mean rise in heart rate of $3 \mathrm{bpm}$ and $5 \mathrm{bpm}$ in groups $A$ and $B$ ( $p<0.05$ on paired $t$ test), and a mean rise in heart rate of $12 \mathrm{bpm}$ in group $C(p<0.01)$.

There was no appreciable difference between the sodium intake, urinary sodium, or fractional 
sodium excretion of the three groups over the 10 day period. Any natriuretic (diuretic) effect of the medication was probably masked by the high sodium loss which is commonly observed in the urine in infants of these gestations.

Although these drugs in higher doses are reputed to have side effects such as glucose intolerance and 'jitteriness', we observed no such problems. In fact, no serious side effect was attributed to medication in any treatment group.

\section{Discussion}

Our study confirmed the efficacy of the methylxanthine drugs, caffeine and theophylline, in the treatment of neonatal apnoea. However, unlike previous reports, ${ }^{3} 8-10$ our study is based on infants of lower gestational age (less than 31 weeks); these infants were oxygen dependent. Furthermore, there is no previous information on the response rate in relation to caffeine dosage.

Our results clearly showed a significant rapid reduction in apnoeic attacks within eight hours in infants receiving higher doses of caffeine (plasma concentration approximately $30 \mathrm{mg} / \mathrm{l}$ ) and theophylline. A rapid response to treatment is valuable and often desirable as intubation or reintubation for ventilation may be avoided.

Despite using a higher caffeine dose, the plasma drug concentrations in all infants were well within the reported therapeutic range. ${ }^{3}$ Our highest caffeine concentration was $68 \mathrm{mg} / \mathrm{l}$. None of our infants on the higher dose of caffeine suffered any adverse side effects. Anyway, side effects such as glucose intolerance, appreciable tachycardia $(>200 \mathrm{bpm})$ and 'jitteriness' are thought to be rare with plasma caffeine concentrations below $80 \mathrm{mg} / \mathrm{l}$.

In our experience plasma caffeine concentrations were more likely to fall within the predicted range than theophylline, when the drugs were given orally, suggesting better absorption of caffeine. In addition, the known longer half life of caffeine and its higher therapeutic ratio, enable fewer blood tests when using caffeine to treat neonatal apnoea.
In conclusion, our study has shown that caffeine (in the higher dose studied) and theophylline (in a standard dosage) are effective in reducing apnoeic attacks within eight hours, even in oxygen dependent infants of less than 31 weeks' gestational age. However, we recommend the use of caffeine because of the many advantages of this drug over theophylline.

Our current practice is to treat symptomatic babies with the higher dose caffeine schedule described here, and to measure plasma concentrations of caffeine only if there is inadequate clinical response.

The authors would like to express their thanks to all the nursing staff in the Regional Neonatal Intensive Care Unit for so carefully documenting the apnoeas - and for keeping so many small babies breathing. Without their skills this study would not have been possible. Our thanks are also due to Dr George Rylance at Birmingham Children's Hospital for his helpful advice.

1 Daily WJR, Klaus M, Meyer HBP. Apnea in premature infants: monitoring, incidence, heart rate changes and an effect of environmental temperature. Pediatrics 1969;43: $510-8$

2 Alden ER, Mandelbain T, Woodrum DE, Wennberg RP, Parks CR, Hodson A. Morbidity and mortality of infants weighing less than 1000 grams in an intensive care nursery. Pediatrics 1972;50:40-9.

3 Aranda JV, Grondin D, Sasyniuk BI. Pharmacologic considerations in the therapy of neonatal apnea. Pediatr Clin North Am 1981;28:113-33.

4 Roberton NRC. Recurrent apnoea of prematurity. A manual of neonatal intensive care. London: Edward Arnold, 1981: $100-2$

5 Durbin GM Insley J. The neonate: prevention and management of illness. In: Insley J, ed. A paediatric vade-mecum. London: Lloyd-Luke, 1986:82.

6 Aranda JV, Cook CE, Gorman W, et al. Pharmacokinetic profile of caffeine in the premature infant with apnea. $\mathcal{f}$ Pediatr 1979;94:663-8.

7 Davis JM, Spitzer AR, Stefano JL, Bhutani V, Fox WW. Use of caffeine in infants unresponsive to theophylline in apnea of prematurity. Pediatr Pulmonol 1987;3:90-3.

8 Aranda JV, Turmen T. Methylxanthines in apnea of prematurity. Clin Perinatol 1979;6:87-108.

9 Brouard C, Moriette G, Murat I, Flouvat B, Pajot N, Walti $\mathrm{H}$, et al. Comparative efficacy of theophylline and caffeine in the treatment of idiopathic apnoea in premature infants. in the treatment of idiopathic apnoea

10 Bairam A, Boutroy M-J, Badonnel Y, Vert P. Theophylline versus caffeine: comparative effects in the treatment of versus caffeine: comparative effects in the treatment of
idiopathic apnea in the preterm infants. $\mathcal{F}$ Pediatr 1987;110: idiopathic $636-9$.

11 Boutroy M-J, Vert P. Royer RJ, Monin P, Royer MJ. Caffeine: a metabolite of theophylline during the treatment of apnea in the premature infant. F Pediatr 1979;94:996-8.

12 Newell SJ, Booth IW, Morgan MEI, Durbin GM, McNeish AS. Gastro-oesophageal reflux in preterm infants. Arch Dis Child 1989;64:780-6. 